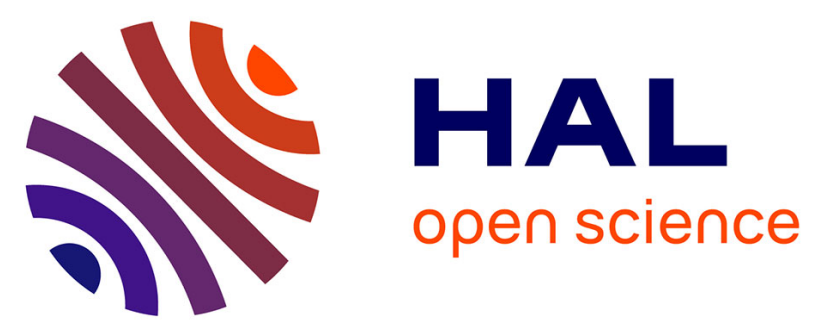

\title{
Outcomes of functional treatment versus open reduction and internal fixation of condylar mandibular fracture with articular impact: A retrospective study of 83 adults
} F-L Merlet, F. Grimaud, Richard Pace, J-M Mercier, M. Poisson, A. Pare, P. Corre

\section{To cite this version:}

F-L Merlet, F. Grimaud, Richard Pace, J-M Mercier, M. Poisson, et al.. Outcomes of functional treatment versus open reduction and internal fixation of condylar mandibular fracture with articular impact: A retrospective study of 83 adults. Journal of Stomatology, Oral and Maxillofacial Surgery, 2018, 119 (1), pp.8 - 15. 10.1016/j.jormas.2017.10.007 . inserm-01856305

\section{HAL Id: inserm-01856305 https://www.hal.inserm.fr/inserm-01856305}

Submitted on 9 Mar 2021

HAL is a multi-disciplinary open access archive for the deposit and dissemination of scientific research documents, whether they are published or not. The documents may come from teaching and research institutions in France or abroad, or from public or private research centers.
L'archive ouverte pluridisciplinaire HAL, est destinée au dépôt et à la diffusion de documents scientifiques de niveau recherche, publiés ou non, émanant des établissements d'enseignement et de recherche français ou étrangers, des laboratoires publics ou privés. 


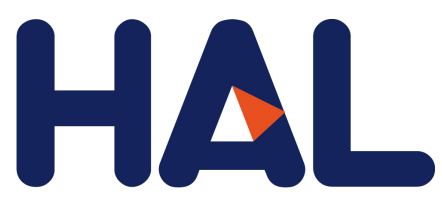

archives-ouvertes

\section{Outcomes of functional treatment versus open reduction and internal fixation of condylar mandibular fracture with articular impact: A retrospective study of $\mathbf{8 3}$ adults}

F. Merlet, F. Grimaud, Richard Pace, M. Mercier, M. Poisson, A. Pare, P. Corre

\section{To cite this version:}

F. Merlet, F. Grimaud, Richard Pace, M. Mercier, M. Poisson, et al.. Outcomes of functional treatment versus open reduction and internal fixation of condylar mandibular fracture with articular impact: A retrospective study of 83 adults. Journal of Stomatology, Oral and Maxillofacial Surgery, Elsevier Masson, 2018, 119 (1), pp.8 - 15. 10.1016/j.jormas.2017.10.007 . inserm-01856305

\section{HAL Id: inserm-01856305 https://www.hal.inserm.fr/inserm-01856305}

Submitted on 9 Mar 2021

HAL is a multi-disciplinary open access archive for the deposit and dissemination of scientific research documents, whether they are published or not. The documents may come from teaching and research institutions in France or abroad, or from public or private research centers.
L'archive ouverte pluridisciplinaire $\mathbf{H A L}$, est destinée au dépôt et à la diffusion de documents scientifiques de niveau recherche, publiés ou non, émanant des établissements d'enseignement et de recherche français ou étrangers, des laboratoires publics ou privés. 


\section{Outcomes of functional treatment versus open reduction and internal fixation of condylar mandibular fracture with articular impact: a retrospective study of 83 adults}

\section{Merlet Fanny-Laure (1), Grimaud Fanny (1), Pace}

Richard (2), Mercier Jacques-Marie(1), Paré Arnaud(3),

\section{Corre Pierre(1)}

. 1) Service de Chirurgie maxillo-faciale et stomatologie, CHU NANTES, 1 place Alexis Ricordeau, 44042 Nantes Cedex 1, France

. 2) Université de Nantes, School of Dental Surgery, Laboratory for Osteoarticular and dental Tissue Engineering : LIOAD, Inserm U791. 1 place Alexis Ricordeau, 44042 Nantes Cedex 1, France

. 3) Service de chirurgie maxillo-faciale, CHRU TOURS, Hopital Trousseau, Rue de le République, 37170 Chambray Les Tours 
Introduction: Treatment of mandibular condylar process fractures remains controversial. This study's aim was to assess the outcomes of isolated functional treatment versus open reduction and internal fixation (ORIF) of mandibular condylar fracture with articular impact based on clinical and radiological criteria.

Materials and methods: Heigthy-three patients with articulary mandibular condylar fracture were included in this retrospective study, divided between two groups: operated and nonoperated patients. Clinical and radiological features were evaluated at various times.

Results: Isolated functional treatment was applied in 55 patients $(66.26 \%), 28$ patients $(33.7 \%)$ were operated using different approaches. Maximal mouth-opening (MMO) was lesser in "operated" group until 6 months $(25.75 \mathrm{~mm}$ vs $31.96 \mathrm{~mm}, 34.76 \mathrm{~mm}$ vs $37.95 \mathrm{~mm}, 38.06 \mathrm{~mm}$ vs $41.87 \mathrm{~mm}$ respectively 1,3 and, 6 months, $\mathrm{p}<0.05)$. There was no difference concerning temporo-mandibular joint dysfunction. At the end of the follow- up, there was no difference between the two groups concerning ramus' height $(p=0.1304$ and 0.6420$)$.

Conclusion: This study showed that an isolated functional treatment which is properly followed provided as good clinical results as ORIF for mandibular condylar fractures with articular impact.

Keywords: Condylar process fracture, Functional treatment, ORIF 


\section{A. Introduction}

Mandibular fractures are the most frequent facial fractures $(1,2)$. Condylar process fractures represent 9 to $45 \%$ of all mandibular fractures (26), and involves the condylar process in $30 \%$ of cases (3-5). Temporo-mandibular joint (TMJ) is often damaged indirectly after an isolated trauma on the chin symphysis, in a multiple trauma context, or associated with other facial fractures. Diagnosis is first made clinically with regards to TMJ pain, chin wound, and occlusal disorder then later confirmed radiologically.

There are multiple consequences associated with TMJ in adults patients. TMJ functional disturbance and pain are typically the first phase where the risk in developing a temporomandibular ankylosis is high (6-8). Other complications include occlusal disorders, facial asymmetry, and TMJ dysfunctional pain $(9,10)$. Although there is no real consensus about the ideal management of these fractures, the treatment is strongly guided by the radiological fracture aspect and its potential functional consequences.

Several classifications of TMJ have been described (11). Loukota et al proposed using the sigmoid notch as an anatomical border to differentiate between high and low condylar process fractures. Condylar base fracture, condylar collum fracture, and diacapitular fractures have been described $(12,13)$. This Loukota classification describes the location of the fracture, but is not sufficient to determine the degree of displacement and dislocation of the condyle which can lead to functional consequences. In clinical practice, the classification according to Spiessl and Schroll has proved to be most useful. The Spiessl and Schroll classification gives anatomic information about the fracture and gives usefull information for surgical treatment. The anatomofunctional classification proposed by Mercier and Perrin $(6,15)$ presents one advantage: it indicates if a specific functional treatment is necessary. It compares articular impact fractures (Type A, B, C), which can cause functional damages on joint structures like disc or capsule, and no articular impact ones.

Condylar base fractures are usually surgically treated, and blocked with maxillo- mandibular fixation if there is a displacement, or with conservative treatment if there is no displacement (10). They typically have a good prognosis $(1,16-18)$

There is still a debate regarding the management of high collum fractures in adults when there is evidence of displacement, dislocation, or diacapitular fractures (19). Following the classification of Spiessl and Schroll, another classification describes by Rasse, Neff (20), Hlawitschka (31), and Loukota (13) have arisen to classify the intraarticular or diacapitular condylar fractures 
according to the fracture line. Type A represents a displacement of medial condylar pole with preservation of the vertical dimension. Type B suggests the lateral condylar pole is involved with loss of the vertical dimension. Type $C$ corresponds to class V according to Spiessl and Schroll: high collum fractures with dislocation. These fractures present the same features as articular impact fractures of Mercier's classification. Treatment of condylar neck fractures with articular impact still remains controversial due to surgical difficulty in obtaining anatomic reduction which limits indications of surgical treatment(2).

It is necessary to assess the benefit versus risk when proposing ORIF. Proponents of surgical treatment estimate that restoring the anatomy and using rigid fixation allows a better recovery of the articular function $(21,22)$. The surgical approach is chosen according to the location of the fracture, the association with other fractures, the risk of esthetic consequences (23), and the surgeon's familiarity (24). The surgical treatment has its limits however $(5,25)$ : the reduction of the fracture and osteosynthesis could be difficult and precarious. Dysesthetic scars, damage to facial nerves, and occurrences of salivary fistula $(23,26)$ represent the most common complications. In fact, merely opening the TMJ attempting to reduce the fracture can cause damage to the intra-articular structures and be responsible for functional sequelae.

Functional treatment exists as an alternative to the surgical treatment, which consists of immediate mobilization of the mandible on projection. Functional treatment is most often used in condylar fractures for children (27). The mobilization of the joint has been shown to induce and accelerate condylar remodeling (28-30). This treatment described by Delaire et al. (7) is based on the repeated actuation of the centered protrusive mandibular and lateral excursion (active reeducation) sometimes associated with elastic traction on arches (passive reeducation).

The purpose of this study was to evaluate the clinical and radiological outcomes of the isolated functional treatment in the case of condylar process fracture with articular impact in adults, in comparison with surgical treatment.

\section{B. Materials and methods}

From January 2009 to December 2015, 83 patients older than 15 years and 3 months presented with either unilateral or bilateral mandibular condylar fracture with articular impact according to Mercier classification were included. These fractures correspond to a high condylar process according to Loukota's, class III, V, and VI according to Spiessl and Schroll and type ABC. Patients with other kinds of condylar process fractures, or other facial fractures involving occlusal disorder were excluded. Additionally, patients younger than 15 or whose follow-up 
period was shorter than 3 months were excluded. In this retrospective study, no change to the current clinical practice or randomization was performed. An ethics committee approval was not required in order to use these data in the epidemiologic study, as per French legislation article L.1121-1 paragraph 1 and R1121-2 of the Public Health Code.

\section{Clinical data}

Data collection was done at 1, 3, 6 months, and 1 year after the trauma. The amplitude of maximal mouth opening (MMO), lateral excursion of the affected condyle, and projection were recorded. Temporo-mandibular joint dysfunction and pain were noted. In operated patients, the scar appearance and facial palsy were noted one year after surgery.

\section{Radiological data}

Radiological exams were analyzed by two different reviewers to characterize the condylar process fracture and to measure the height of the ramus.

\section{a) Classification of the fractures}

Fractures were initially classified according to Loukota, Spiessl and Schroll, Mercier and subdivided to $A, B$ and $C$. If a difference occurred, exams were analyzed by a third reviewer.

\section{b) Height of the ramus}

Secondly, the height of the ascending ramus was measured between the top of the condylar process and the distal part of the angular notch on initial radiological exam, 6 weeks later after complete bone healing, and at the end of the follow-up. Measurements were either performed on a panoramic X-ray or on three-dimensional (3D) reconstructions from CBCT (fig. 3).

In unilateral fractures, measurement of the ascending ramus allows us to calculate a percentage of the initial and final loss of height. If there were differences, exams were analyzed by the 2 reviewers together. For this result, bilateral fractures were not considered.

\section{c) Chin position and occlusal plan}

Analysis of three-dimensional reconstructions allowed us to assess the consequences of the fracture on facial and mandibular symmetries. We analyzed chin position and horizontal correction of the occlusal plan at the end of follow-up. Two reference lines were used for the frontal analysis. The supra-orbital line joining the top of the orbital roofs served as one reference 
line, while the occlusal plan passing through occlusal points of first molars served as the other (fig. 4).

\section{d) Condylar remodelling}

Condylar remodeling was analyzed from the last X-ray control if it was performed at least 3 months after the traumatism, and only for non-operated patients. Remodeling quality was classified in 3 levels as previously defined by Gilhuus-Moe (32). Two reviewers then analyzed remodeling and the level was established from the average of the two results.

Complete remodeling (+++): no condylar deformity radiologically, symmetrical condylar processes and symmetrical mandible.

Moderate remodeling $(++)$ : irregular condylar process not grossly malformed with the condyle clearly outlined in both lateral and frontal projections.

Poor remodeling $(+)$ : condyle obviously deformed and irregular in the lateral view.

\section{Treatment}

All patients who presented a condylar process fracture with articular impact benefited from a functional treatment. Surgical treatments were used alongside functional treatments in cases where the fracture was displaced or dislocated leading to a loss of height with major occlusal discomfort.

\section{a) Functional treatment}

Functional treatment refers to Delaire's technique (7). Briefly, it advocates active reeducation with projection and lateral excursion movements along with passive reeducation with elastics placed on vestibular stainless arches made from the patient's dental impression.

\section{b) Surgical treatment}

Two surgical approaches were performed according to the location of the fracture. Either a submandibular transmasseteric approach, a modified Risdon's approach, or a preauricular approach.

\section{Statistical analyses}

Statistical analyses were performed with GraphPad Prism 5.0 for Mac (GraphPad Softwere, La 
Jolla, United States). Quantitative data were compared using a Student's test for independent and paired sample if there were more than 30 values. A Mann-Whitney and a Wilcoxon test were performed for small samples. Qualitative data were compared using $\mathrm{Chi}^{2}$ test. Statistical significance was determined when a $p$-value was less than $0.05(p<0.05)$.

\section{Results 1. Epidemiologic data}

A statistically significant male predominance was observed: $69.9 \%$ of the 83 patients $(p<0.0001)$. The average age was 36.44 years old (15 to 81$)$. The mean follow-up was 14.8 months ( 3 to 72 ). The most common etiology of fractures was due to a fall headlong: in $48 \%$ it was accidents due to dizziness or epileptic crisis. All of the epidemiological data are summarized in table 2.

\section{Clinical data}

A statistically significant difference was observed concerning MMO between operated, and nonoperated patients until 6 months $(p<0.05)$. However, there was no difference one year after traumatism. $(41.29 \mathrm{~mm}$ and $45.22 \mathrm{~mm} \mathrm{p}=0.2024)$. None of the observed patients presented TMJ ankylosis. The lowest MMO was $30 \mathrm{~mm}$. Lateral excursion was more severe for non-operated patients whatever the deadline. No difference was observed between each group concerning protrusion. All articular movements were collected in table 3 and, figure 5.

We distinguished between unilateral versus bilateral fractures and whether it should influence the MMO. Results are summarized in table 4 . There was no statistically significant difference of MMO between uni- or bilateral fractures.

No statistically significant difference was observed concerning TMJ dysfunctions between operated and non-operated patients. The proportion of this symptom increased with a longer follow-up. All results are summarized in table 5.

\section{Radiological data}

Each reader noted the results of the analysis. Then, averages of data were calculated and compared between the two readers. There was no significant difference between the two readers $(p=0,6687)$.

\section{a) Classification of the fractures}

Table 6 collected fractures distribution according to Loukota, Mercier and Spiessl and Schroll's 
classifications. We classified the intraarticular fractures according to A, B, C classification. All condylar process fractures were noted, but in the study, we considered only condylar process fractures with articular impact.

\section{b) Loss of height}

The loss of height between the two ramus was initially statistically different between operated and non-operated patients $(p=0.0137)$. After surgical correction, the difference was not significant anymore between the two groups early after treatment and at the end of the follow-up $(p=0.1304$ and 0.6420$)$. The difference of ramus height was also statistically different before and after surgery for operated-patients $(p=0.001)$ (table 7$)$.

In bilateral condylar process fractures, there was no statistical significant difference of the average of ramus height between operated and non-operated patients, and this average was not different between before treatment, early after treatment, and at the end of the follow-up.

\section{c) Condylar remodeling}

We analyzed condylar process remodeling in non-operated patients who presented intraarticular fractures. Results are collected in Table 9.

\section{d) Chin position and occlusal plan}

Eight patients had their occlusion plan inclined at the end of the follow-up ( 3 non- operated patients and 5 operated patients). The average of tilted occlusal plan for operated patients was $7.244^{\circ}$ and $4.243^{\circ}$ for non-operated patients $(p=0.25)$.

\section{Therapeutic data}

All patients benefited from functional reeducation. 77 patients $(92.77 \%)$ underwent passive reeducation with arches while $6(7.23 \%)$ patients did only active reeducation.

Twenty-eight patients (33.7\%) and 36 intraarticular fractures underwent surgical treatment (table 10):

- 8 patients : bilateral pre-auricular approaches - 8 patients : unilateral pre-auricular approach 9 patients : unilateral modified RISDON's approach - 3 patients : modified RISDON's approach

+ pre-auricular approach

Among the 28 patients who were operated, 26 presented a satisfactory scar. One scar (3.57\%) 
was indurated and one (3.57\%) was colored. None suffered from facial paralysis one year after the operation.

Two patients $(7.14 \%)$ presented secondary movements after surgery which did not require a new surgical intervention. There was no functional consequence. These two patients presented type C (IV) fractures.

One patient (3.57\%) required a new surgical intervention one year after traumatism because of contact between the osteosynthesis screw and the skull base. It was type B fracture.

\section{Discussion}

The purpose of this study was to evaluate the outcomes of the isolated functional treatment in the case of condylar process fracture with articular impact in adults, in comparison with surgical treatment.

In our study, 83 patients were included and a male predominance was revealed, agreeing with many other studies $(1,8,23,24,33)$. Etiologies were different between males and females where males have riskier behavior $(24,34,35)$ : fights, road traffic accidents, sports. The most frequent condylar process fractures' etiologies for females were accidental falls or after dizziness.

Patients' average age of our study was 36.44 years old. This result is older than other studies $(24,34)$ which is between 20 and 30 years old. We can explain this difference because we included only patients older than 15 years old. Children were excluded because their treatment for this kind of fracture is always functional $(15,28,29)$.

We noted $35 \%$ chin wounds and $36 \%$ dental injuries. These results show the importance of looking for condylar process fractures when these symptoms are present.

Many classifications exist to describe condylar process fractures $(6,12,13,24)$. We choose to base our study on Loukota and Spiessl and Schroll's classifications, because they are very often used in the literature and is currently considered as the basis for many comparative studies $(11,23,36-39)$. However, Spiessl and Schroll's classification doesn't explicitly demarcate the degree of displacement or dislocation which could be relevant to the prognosis. Moreover, it doesn't allow the classification of all kinds of high condylar process fractures as shown in table 6 . That is why we also referred to Mercier's and "ABC" classifications because they bring interesting therapeutic prospects. The existence of a lot of classifications made comparative studies more difficult (40). We thus tried to link Spiessl and Schroll, Mercier, and "ABC" 
classifications to clarify our purpose (table 11).

In our study, $33.7 \%$ of patients underwent surgical treatment. None type A patients, was operated. We didn't operate type A fractures because in these cases, there was a preservation of the vertical dimension and occlusion that represented an operating criteria for us. However, $32.8 \%$ of type $B$ and $45 \%$ of type $C$ patients did undergo surgical treaments. Trost et al $(16,41)$ in 2013 showed a tendency was towards surgery with $82 \%$ of operated high collum fractures (versus $29 \%$ in 2005) and $35 \%$ of diacapitular fractures (versus $10 \%$ in 2005).

Condylar process surgical approaches are varied (26,42-44). We differentiate extraoral and endoscopically assisted intraoral approaches. The advantages of intraoral approaches include a lack of noticeable scar and reduction of risk for facial nerve damage. However osteosynthesis is generally more difficult because of a smaller exposition (42). In our study, we used only extraoral approaches with modified Risdon's approach and preauricular approach. No damage to the facial nerve was noted while scars were discrete and without aesthetic discomfort which validate the approaches we chose when compared to other reports $(25,36,45)$. Only one patient, complaining from TMJ one year after surgery, needed to be reoperated upon to remove a screw in contact with the skull base.

Seeman et al (46) observed that osteosynthesis failure occurs in $11.8 \%$ to $17.4 \%$ of patients. In their study, the best predictor of osteosynthesis failure was based on the ramus height. In cases of reduced or normal height, the odds of osteosynthesis failure was significantly reduced by a factor of 10. There was a significantly higher risk of osteosynthesis failure rate when no other mandibular fracture existed $(47,48)$. In our study, the 2 patients who presented with secondary movements after surgery had isolated condylar process fractures as well.

TMJ early mobilization is highly recommended by most of authors $(1,16,21)$. Early maxillamandibular elastics physiotherapy was used for $92.77 \%$ of patients. One patient who didn't benefit initially from maxillo-mandibular physiotherapy arches, needed it secondarily (4 months later) because of persistent occlusal trouble.. In literature, a few surgical teams use functional treatment with diurnal active and passive physiotherapy and nocturnal maxilla-mandibular fixation. After surgery, diurnal maxilla-mandibular fixation is generally suggested because it causes limits mandibular motions $(11,49)$, and can be used nightly to promote bone healing. .

In the present study, mouth opening was significantly higher in non-operated patients until 6 months after traumatism. It became none significant 1 year after traumatism. MMO was higher than on average $40 \mathrm{~mm}$ at the end for both groups, demonstrating that conservative 
management including early functional treatment could result in restoring TMJ function. Initial lower MMO for operated patients could be explained by the more displaced fractures in this group. Better mouth-opening recovery for non-operated

patients could be due to earlier reeducation of non-operated patients that started just after the diagnosis. On the other side, postoperative pain probably limited articular motions and prevented an early recovery in operated patients. Other predictive factors of poor recovery are displaced, multiple, bilateral fractures in elder patients (50). In our study we did not observe any difference in mouth opening between uni- or bilateral at the end of the follow-up. It could be more difficult for old patients to understand reeducation principles and, thus cause poorer results. Three patients were more than 75 years old, and their average MMO was $38 \mathrm{~mm} 6$ months after traumatism. No ankylosis was noted in any of the patients. Throckmorton (49) showed complete MMO recovery 3 years after traumatism concerning operated or non-operated patients. Furthermore, he noted that the longer the MMF period, the longer the time required for recovery. With regard to lateral excursion, it was always more significant in non-operated patients than operated ones. This result agrees with Danda et al (51) and, Haug and Assael (52). In some cases of the present study, we observed a good fracture reduction and functional treatment completion, but with inadequate functional results. In these particular cases it could have been interesting to look for TMJ's elements damages (disk, capsule) with MRI $(42,53,54)$. Unfortunately, these data were not available in the present study since MRI is not part of our condylar fracture management protocol to date.

There was no statistically significant difference concerning TMJ dysfunction between the two groups. According to Ellis (9) TMJ dysfunction is increased by condylar process displacement, MMF period and patient's age. We didn't notice such difference.

In the present study, the condylar process remodeling observed in adults after functional treatment alone was lower than in children for the same fracture (55). One possible long term response of high condylar process fracture is bifid condyle. One case of bifid condyle was discovered by chance in the study in the group "non-operated". Another patient of our department who complained about TMJ pain 20 years after condyle fracture presented with the same feature. This unusual condylar process from congenital or secondary cause usually requires medical treatment. (56).

Difference in ramus height was initially significantly different between operated and nonoperated patients (16.34\% for operated versus $7.76 \%$ for others). After surgery, both groups didn't show difference anymore. As expected, ORIF allowed for the restoration of 
the ramus height (22). This result induced bias between the two groups because initial fractures in operated group were more displaced (40) which probably caused more occlusal trouble and TMJ damages. In the present study, patients were not randomized regarding the loss of height of the ramus. We assumed that the more displaced fractures were less able to remodel than fractures with little displacement. According to literature, there is no consensus in the required loss of height before suggesting ORIF. Schneider et al consider that a difference in ramus height more than $2 \mathrm{~mm}$ is a surgical indication $(4,57,58)$ whereas Sugiura et al $(59)$ consider only a loss of height greater than $7 \mathrm{~mm}$. That was our choice in this study since the mean difference between ramus was about $11 \mathrm{~mm}$.

We acknowledge some flaws in our study. First, as a retrospective study, data collection was based on medical files and data were sometimes missing. Moreover, as frequent in traumatology studies, many patients were lost to follow-up. Overall, in opposition to Neff et al(20) who affirmed that conservative treatment of TMJ condylar fractures often showed poor clinical results, our study tended to demonstrate that functional treatment only provided equal results as ORIF when followed by functional treatment.. Although this retrospective study suffers many biases, it could provide relevant data to start a randomized prospective study.

\section{E. Conclusion}

Properly followed functional treatment of condylar process mandibular fractures with articular impact provides satisfactory clinical results. Early mobilization is essential. However, when fractures are too displaced or dislocated, surgical treatment is necessary to restore ramus height. 
1. Zachariades N, Mezitis M, Mourouzis C, Papadakis D, Spanou A: Fractures of the mandibular condyle: a review of 466 cases. Literature review, reflections on treatment and proposals. $J$ Craniomaxillofac Surg 34: 421-32, 2006

2. Schneider M, Lauer G, Eckelt U: Surgical treatment of fractures of the mandibular condyle: a comparison of long-term results following different approaches - functional, axiographical, and radiological findings. J Craniomaxillofac Surg 35: 151-60, 2007

3. Ellis E, Throckmorton GS: Treatment of mandibular condylar process fractures: biological considerations. J Oral Maxillofac Surg 63: 115-34, 2005

4. Eckelt U, Schneider M, Erasmus F, Gerlach KL, Kuhlisch E, Loukota R, and al: Open versus closed treatment of fractures of the mandibular condylar process-a prospective randomized multi-centre study. J Craniomaxillofac Surg 34: 306-14, 2006

5. Rutges JPHJ, Kruizinga EHW, Rosenberg A, Koole R: Functional results after conservative treatment of fractures of the mandibular condyle. Br J Oral Maxillofac Surg 45: 30-4, 2007

6. Mercier J, Huet P, Perrin JP: Functional management of fractures of the mandibular condyle. Rev Stomatol Chir Maxillofac 10: 203-6, 2000

7. Delaire J, Le Roux J, Tulasne JF: Functional treatment of fractures of the mandibular condyle and its neck. Rev Stomatol Chir Maxillofac 76: 331-50, 1975

8. Amaratunga NA: A study of condylar fractures in Sri Lankan patients with special reference to the recent views on treatment, healing and sequelae. Br J Oral Maxillofac Surg 25: 391-7, 1987

9. Ellis E: Complications of mandibular condyle fractures. Int J Oral Maxillofac Surg 27: 255-7, 1998

10. Kadlub N, Trost O, Duvernay A, Parmentier J, Wirth C, Malka G: Orthopaedic treatment of extraarticular condylar fractures of the mandible: retrospective study of 39 unilateral cases. Rev Stomatol Chir Maxillofac 109: 301-6, 2008

11. Handschel J, Rüggeberg T, Depprich R, Schwarz F, Meyer U, Kübler NR, and al: Comparison of various approaches for the treatment of fractures of the mandibular condylar process. J Craniomaxillofac Surg 40: 397-401,.2012

12. Loukota RA, Eckelt U, De Bont L, Rasse M: Subclassification of fractures of the condylar 
process of the mandible. Br J Oral Maxillofac Surg 43: 72-3, 2005

13. Loukota RA, Neff A, Rasse M: Nomenclature/classification of fractures of the mandibular condylar head. Br J Oral Maxillofac Surg 48: 477-8, 2010

14. Schneider M, Lauer G, Eckelt U: Surgical treatment of fractures of the mandibular condyle: a comparison of long-term results following different approaches - functional, axiographical, and radiological findings. J Craniomaxillofacial Surg 35: 151-160, 2007

15. Mercier J, Lemoine V, Gaillard A, Delaire J: Results of treatment of mandibular fractures in 27 children. Rev Stomatol Chir Maxillofac 8: 296-300, 1980

16. Trost O, Péron J-M: Latest trends in the surgical management of mandibular condyle fractures in France, 2005-2012. Rev Stomatol Chir Maxillo-Faciale Chir Orale 114: 341-8, 2013

17. Kommers SC, Boffano P, Forouzanfar T: Consensus or controversy? The classification and treatment decision-making by 491 maxillofacial surgeons from around the world in three cases of a unilateral mandibular condyle fracture. J Craniomaxillofac Surg 43: 1952-60, 2015

18. Gupta M, lyer N, Das D, Nagaraj J: Analysis of different treatment protocols for fractures of condylar process of mandible. J Oral Maxillofac Surg 70: 83-91, 2012

19. Ellis E: Method to determine when open treatment of condylar process fractures is not necessary. J Oral Maxillofac Surg 67:1685-90, 2009

20. Neff A, Kolk A, Deppe $\mathrm{H}$, Horch $\mathrm{HH}$ : New aspects for indications of surgical management of intra-articular and high temporomandibular dislocation fractures. Mund- Kiefer- Gesichtschirurgie 3: 24-9, 1999

21. Meyer C: Fractures of the condylar region: functional treatment or surgery?. Rev Stomatol Chir Maxillofac 107: 133-5, 2006

22. Kolk A, Neff A: Long-term results of ORIF of condylar head fractures of the mandible: A prospective 5-year follow-up study of small-fragment positional-screw osteosynthesis. J

Craniomaxillofacial Surg 43: 452-61, 2015.

23. Klatt J, Pohlenz P, Blessmann M, Blake F, Eichhorn W, Schmelzle R, and al: Clinical followup examination of surgically treated fractures of the condylar process using the transparotid approach. J Oral Maxillofac Surg 68: 611-7, 2010 
24. Zhou H-H, Liu Q, Cheng G, Li Z-B: Aetiology, pattern and treatment of mandibular condylar fractures in 549 patients: a 22-year retrospective study. J Craniomaxillofac Surg 2013 41: 34-41, 2013

25. Ellis E, McFadden D, Simon P, Throckmorton G: Surgical complications with open treatment of mandibular condylar process fractures. J Oral Maxillofac Surg 58: 950-8, 2000

26. Schmelzeisen R, Cienfuegos-Monroy R, Schön R, Chen C-T, Cunningham L, Goldhahn S: Patient benefit from endoscopically assisted fixation of condylar neck fractures-a randomized controlled trial. J Oral Maxillofac Surg 67: 147-58, 2009

27. Sawhney R, Brown R, Ducic Y: Condylar fractures. Otolaryngol Clin North Am 46: 779-90, 2013

28. Zhao Y, Yang J, Bai R, Ge L, Zhang Y: A retrospective study of using removable occlusal splint in the treatment of condylar fracture in children. J Craniomaxillofac Surg 42: 1078-82, 2014

29. Chrcanovic BR: Open versus closed reduction: mandibular condylar fractures in children. Oral Maxillofac Surg 16: 245-55, 2012

30. Tuna EB, Dündar A, Çankaya AB, Gençay K: Conservative Approach to Unilateral Condylar Fracture in a Growing Patient: A 2.5-Year Follow Up. Open Dent J 12:1-4, 2012

31. Hlawitschka M, Eckelt $U:$ Assessment of patients treated for intracapsular fractures of the mandibular condyle by closed techniques. J Oral Maxillofac Surg 60: 784-92, 2002

32. Gilhuus-Moe O: Fractures of the mandibular condyle in the growth period. Histologic and autoradiographic observations in the contralateral, nontraumatized condyle. Acta Odontol Scand 29: 53-63, 1971

33. Villarreal PM, Monje F, Junquera LM, Mateo J, Morillo AJ, González C: Mandibular condyle fractures: determinants of treatment and outcome. J Oral Maxillofac Surg. 62: 155-63, 2004

34. Ellis E, Moos KF, el-Attar A: Ten years of mandibular fractures: an analysis of 2,137 cases. Oral Surg Oral Med Oral Pathol. 59: 120-9, 1985

35. Silvennoinen U, lizuka T, Lindqvist C, Oikarinen K: Different patterns of condylar fractures: 
an analysis of 382 patients in a 3-year period. J Oral Maxillofac Surg 50: 1032-7, 1992

36. Landes CA, Day K, Lipphardt R, Sader R: Closed versus open operative treatment of nondisplaced diacapitular (Class VI) fractures. J Oral Maxillofacial surg 66: 1586-94, 2008

37. Landes CA, Day K, Glasl B, Ludwig B, Sader R, Kovács AF: Prospective evaluation of closed treatment of nondisplaced and nondislocated mandibular condyle fractures versus open reposition and rigid fixation of displaced and dislocated fractures in children. J Oral Maxillofac Surg 66: 1184-93, 2008

38. Landes CA, Lipphardt R: Prospective evaluation of a pragmatic treatment rationale: open reduction and internal fixation of displaced and dislocated condyle and condylar head fractures and closed reduction of non-displaced, non-dislocated fractures Part II: high condylar and condylar head fractures. Int J Oral Maxillofac Surg 35: 115-26, 2006

39. Boehle AP, Herrmann E, Ghanaati S, Ballon A, Landes CA: Transoral vs. extraoral approach in the treatment of condylar neck fractures. J Craniomaxillofac Surg 43: 224-31, 2015

40. Berner T, Essig H, Schumann P, Blumer M, Lanzer M, Rücker $M$, and al: Closed versus open treatment of mandibular condylar process fractures: A meta-analysis of retrospective and prospective studies. J Craniomaxillofac Surg 43: 1404-8, 2015

41. Trost O, Kadlub N, Abu El-Naaj I, Danino A, Trouilloud P, Malka G: Surgical management of mandibular condylar fractures in adults in France, 2005. Rev Stomatol Chir Maxillofac 108: 1838,2007

42. Jensen T, Jensen J, Nørholt SE, Dahl M, Lenk-Hansen L, Svensson P: Open reduction and rigid internal fixation of mandibular condylar fractures by an intraoral approach: a long- term follow-up study of 15 patients. J Oral Maxillofac Surg 64: 1771-9, 2006

43. Lutz J-C, Clavert P, Wolfram-Gabel R, Wilk A, Kahn J-L: Is the high submandibular transmasseteric approach to the mandibular condyle safe for the inferior buccal branch? Surg Radiol Anat 32: 963-9, 2010

44. Manisali M, Amin M, Aghabeigi B, Newman L: Retromandibular approach to the mandibular condyle: a clinical and cadaveric study. Int J Oral Maxillofac Surg 32: 253-6, 2003

45. Vesnaver A, Ahčan U, Rozman J: Evaluation of surgical treatment in mandibular condyle fractures. J Craniomaxillofac Surg 40: 647-53, 2012 
46. Seemann R, Undt G, Lauer G, Holawe S, Schicho K, Czerny C, and al: Is failure of condylar neck osteosynthesis predictable based on orthopantomography? Oral Surg Oral Med Oral Pathol Oral Radiol Endod 111: 362-71, 2011

47. Seemann R, Frerich B, Müller S, Koenke R, Ploder O, Schicho K, and al: Comparison of locking and nonlocking plates in the treatment of mandibular condyle fractures. Oral Surg Oral Med Oral Pathol Oral Radiol Endod 108: 328-34, 2009

48. Seemann R, Perisanidis C, Schicho K, Wutzl A, Poeschl WP, Köhnke R, and al: Complication rates of operatively treated mandibular fractures of the mandibular neck. Oral Surg Oral Med Oral Pathol Oral Radiol Endod 109: 815-9, 2010

49. Throckmorton GS, Ellis E: Recovery of mandibular motion after closed and open treatment of unilateral mandibular condylar process fractures. Int J Oral Maxillofac Surg.29: 421-7, 2000

50. Niezen ET, Stuive I, Post WJ, Bos RRM, Dijkstra PU: Recovery of mouth-opening after closed treatment of a fracture of the mandibular condyle: a longitudinal study. $\mathrm{Br} \mathrm{J}$ Oral Maxillofac Surg 53: 170-5, 2015

51. Danda AK, Muthusekhar MR, Narayanan V, Baig MF, Siddareddi A: Open versus closed treatment of unilateral subcondylar and condylar neck fractures: a prospective, randomized clinical study. J Oral Maxillofac Surg 68: 1238-41, 2010

52. Haug RH, Assael LA: Outcomes of open versus closed treatment of mandibular subcondylar fractures. J Oral Maxillofac Surg 59: 370-6, 2001

53. Hlawitschka M, Loukota R, Eckelt U: Functional and radiological results of open and closed treatment of intracapsular (diacapitular) condylar fractures of the mandible. Int J Oral Maxillofac Surg 34: 597-604, 2005

54. Kim BC, Lee YC, Cha HS, Lee S-H: Characteristics of temporomandibular joint structures after mandibular condyle fractures revealed by magnetic resonance imaging. Maxillofac Plast Reconstr Surg 38: 24,30, 2016

55. Lindahl L, Hollender L: Condylar fractures of the mandible. A radiographic study of remodeling processes in the temporomandibular joint. Int J Oral Surg 6: 153-65, 1977

56. Khonsari R-H, Corre P, Bouguila J, Lumineau J-P, Heuzé Y: Bifid mandibular condyle: 
position of the supernumerary condyle. Rev Stomatol Chir Maxillofac 111: 221-4, 2010

57. Schneider M, Erasmus F, Gerlach KL, Kuhlisch E, Loukota RA, Rasse M, and al: Open reduction and internal fixation versus closed treatment and mandibulomaxillary fixation of fractures of the mandibular condylar process: a randomized, prospective, multicenter study with special evaluation of fracture level. J Oral Maxillofac Surg Off J Am Assoc Oral Maxillofac Surg 66: $2537-44,2008$

58. Kommers S, Moghimi M, Van de Ven L, Forouzanfar T: Is radiological shortening of the ramus a reliable guide to operative management of unilateral fractures of the mandibular condyle? Br J Oral Maxillofac Surg 52: 491-5, 2014

59. Sugiura T, Yamamoto K, Murakami K, Sugimura M: A comparative evaluation of osteosynthesis with lag screws, miniplates, or Kirschner wires for mandibular condylar process fractures. J Oral Maxillofac Surg Off J Am Assoc Oral Maxillofac Surg 59: 1161-70, 2001 
Table 1 : General characteristics of the patients

\begin{tabular}{ll}
\hline Sex : females/males, $\mathbf{n}(\%)$ & $25(30.1) / 58(69.9)$, \\
Affected side : left/right/bilateral, n(\%) & $25(30.12) / 21(25.30) / 38(45.78)$ \\
Age of diagnosis, means (years), range (years) & $36.44(15-81)$ \\
Follow-up duration (months), range (months) & $14.8(3-72)$ \\
Etiologies (\%) & Fall headlong: 48 \\
& Road traffic accident : 35 \\
& High kinetic fall : 7 \\
& Fight : 6 \\
& Other (sport, projections) : 4 \\
& Associated mandibular fractures : 51 \\
& $(61.4)$ \\
Associated injuries $\mathbf{n}(\%)$ & Dental injuries : $30(36.1)$ \\
& Chin wound : $29(34.9)$ \\
& Maxillary fractures : $4(4.8)$ \\
Nose fractures : $3(3.6)$
\end{tabular}

$\mathrm{n}$ : number of patients

Table 2: Articular movements analysis, mm

\begin{tabular}{|c|c|c|c|c|c|c|c|c|c|c|c|c|}
\hline & \multicolumn{4}{|c|}{ MMO } & \multicolumn{4}{|c|}{ LT } & \multicolumn{4}{|c|}{ Propulsion } \\
\hline & $1 \mathrm{M}$ & $3 \mathrm{M}$ & $6 \mathrm{M}$ & $12 \mathrm{M}$ & $1 \mathrm{M}$ & $3 \mathrm{M}$ & $6 \mathrm{M}$ & $12 \mathrm{M}$ & $1 \mathrm{M}$ & $3 \mathrm{M}$ & $6 \mathrm{M}$ & $12 \mathrm{M}$ \\
\hline 0 & $\begin{array}{c}25.76 \\
(n=23)\end{array}$ & $\begin{array}{c}34.76 \\
(n=23)\end{array}$ & $\begin{array}{l}38.06 \\
(n=17)\end{array}$ & $\begin{array}{l}41.29 \\
(n=10)\end{array}$ & $\begin{array}{c}4.779 \\
(n=34)\end{array}$ & $\begin{array}{c}6.121 \\
(n=33)\end{array}$ & $\begin{array}{c}7.500 \\
(n=22)\end{array}$ & $\begin{array}{c}7.333 \\
(n=18)\end{array}$ & $\begin{array}{l}2.909 \\
(n=11)\end{array}$ & $\begin{array}{l}3.389 \\
(n=9)\end{array}$ & $\begin{array}{l}3.100 \\
(n=5)\end{array}$ & $\begin{array}{l}3.500 \\
(n=4)\end{array}$ \\
\hline NO & $\begin{array}{c}31.96 \\
(n=55)\end{array}$ & $\begin{array}{c}37.95 \\
(n=44)\end{array}$ & $\begin{array}{c}41.87 \\
(n=33)\end{array}$ & $\begin{array}{c}45.22 \\
(n=21)\end{array}$ & $\begin{array}{c}6.362 \\
(n=69)\end{array}$ & $\begin{array}{l}8.459 \\
(n=61)\end{array}$ & $\begin{array}{c}9.085 \\
(n=47)\end{array}$ & $\begin{array}{c}9.276 \\
(n=29)\end{array}$ & $\begin{array}{l}2.793 \\
(n=29)\end{array}$ & $\begin{array}{l}3.345 \\
(n=29)\end{array}$ & $\begin{array}{c}3.684 \\
(n=19)\end{array}$ & $\begin{array}{l}5.222 \\
(n=9)\end{array}$ \\
\hline$p$ & 0.0013 & 0.0309 & 0.0122 & NS & 0.018 & 0.0006 & 0.0380 & 0.0229 & NS & NS & NS & NS \\
\hline
\end{tabular}

MMO : Maximal mouth opening LT : laterotrusion O : operated NO : non-operated NS : non significant $\mathrm{n}$ : number of patients, M: months

Table 3: Comparison of MMO (mm) according to uni- and bilateral fractures in operated and non-operated patients 


\begin{tabular}{ccccccc}
\hline & & 0 & & & NO & \\
& Unilateral & Bilateral & $p$ & Unilateral & Bilateral & $p$ \\
\hline 1 month & 26 & 24.91 & NS & 32.58 & 30.20 & NS \\
3 months & 34.82 & 34.42 & NS & 38.82 & 36.77 & NS \\
6 months & 40.75 & 34.67 & 0.0489 & 43.13 & 40.09 & NS \\
12 months & 44.33 & 38.38 & NS & 45.69 & 46.50 & NS \\
\hline 0: operated N0: non-operated NS: non-significant & & & & & \\
\hline
\end{tabular}

Table 4 : proportion of TMI dysfunction

\begin{tabular}{ccccc}
\hline & 1 month & 3 months & 6 months & 1 year \\
O & $1(3.57 \%)$ & $1(3.57 \%)$ & $2(7.14 \%)$ & $3(10.71 \%)$ \\
NO & $2(3.64 \%)$ & $5(9.09 \%)$ & $5(9.09 \%)$ & $4(7.27 \%)$ \\
$p$ & NS & NS & NS & NS \\
\hline O: operated NO : non-operated NS : non-significant & & &
\end{tabular}

Table 5 : Fractures distribution according to the different classifications

\begin{tabular}{ccccc}
\hline & & Right & Left & Total \\
\hline \multirow{3}{*}{ LOUKOTA } & Condylar base & 6 & 4 & 10 \\
& Condylar collum & 22 & 22 & 44 \\
& Diacapitular & 31 & 37 & 68 \\
MERCIER & RA+ & 54 & 59 & 113 \\
& RA- & 5 & 4 & 9 \\
SPIESSL and & I & 2 & 1 & 3 \\
SCHROLL & II & 1 & 3 & 4 \\
& III & 4 & 0 & 4 \\
& IV & 3 & 1 & 4 \\
\hline
\end{tabular}




\begin{tabular}{ccccc}
\hline & VI & 27 & 34 & 61 \\
& UC & 5 & 6 & 11 \\
Intraarticular & A & 5 & 6 & 11 \\
fractures & B & 27 & 34 & 61 \\
& C & 17 & 18 & 35 \\
\hline
\end{tabular}

UC : unclassified RA+ : with articular impact RA- : without articular impact

Table 6 : Loss of height between the 2 ramus, $\mathrm{mm},(\%)$ in the case of unilateral condylar process fractures

\begin{tabular}{cccc}
\hline & Before treatment & Early after treatment & Final follow up \\
Operated & $11.21, \mathrm{n}=13$ & $3.242, \mathrm{n}=15$ & $5.208, \mathrm{n}=9$ \\
& $(16.34)$ & $(4.57)$ & $(6.77)$ \\
Non-operated & $5.98, \mathrm{n}=37$ & $5.288, \mathrm{n}=33$ & $4.786, \mathrm{n}=24$ \\
& $(7.76)$ & $(7.27)$ & $(7.64)$ \\
$p$ & 0.0137 & 0.1304 & 0.6420 \\
\hline
\end{tabular}

$\mathrm{n}:$ number of patients

Table 7 : Average of the ramus height, $\mathrm{mm}$, in the case of bilateral condylar process fractures

\begin{tabular}{cccc}
\hline & Before treatment & $\begin{array}{c}\text { Early after } \\
\text { treatment }\end{array}$ & Final follow-up \\
Operated & 61.59 & 65.47 & 64.19 \\
Non-operated & 64.50 & 63.97 & 64.07 \\
$p$ & NS & NS & NS \\
\hline NS: non-significant & & &
\end{tabular}

Table 8: Non-operated condylar remodeling

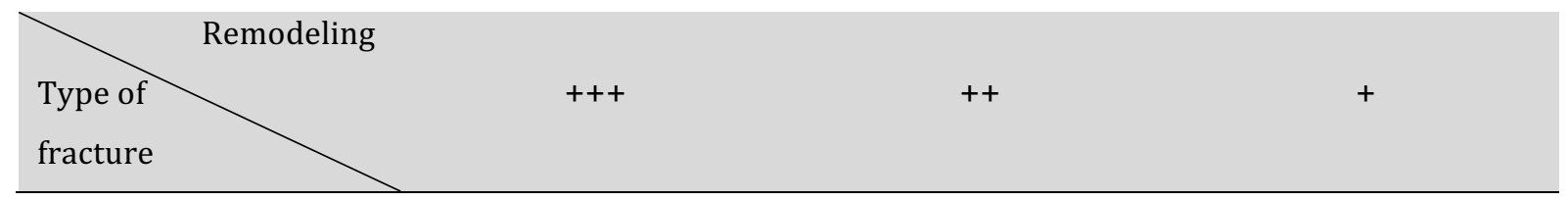




\begin{tabular}{llcl}
\hline A & 5 & 3 & 0 \\
B & 3 & 15 & 7 \\
C & 3 & 4 & 6 \\
\hline
\end{tabular}

+++ : Complete remodeling, ++ : moderate remodeling, + : poor remodeling

Table 9: Distribution of kinds of intraarticular fractures

\begin{tabular}{cccc} 
& A & B & C \\
\hline Operated & 0 & 20 & 16 \\
Non-operated & 11 & 41 & 19 \\
\hline
\end{tabular}

Table 10 : Comparison of classifications

\begin{tabular}{|c|c|c|c|c|c|c|}
\hline & Artic & ar impact fr: & ures & No imp & $t$ articular $f$ & ctures \\
\hline \multirow{2}{*}{$\begin{array}{l}\text { Anatomo- } \\
\text { fonctional } \\
\text { classification }\end{array}$} & \multirow[t]{2}{*}{ Diacapitular } & $\begin{array}{c}\text { High } \\
\text { collum } \\
\text { fractures } \\
\text { with } \\
\text { dislocation }\end{array}$ & $\begin{array}{c}\text { Deep } \\
\text { collum } \\
\text { fractures } \\
\text { with } \\
\text { dislocation }\end{array}$ & \multirow{2}{*}{$\begin{array}{c}\text { Collum } \\
\text { fractures } \\
\text { without } \\
\text { considerable } \\
\text { displacement }\end{array}$} & $\begin{array}{l}\text { Collum } \\
\text { fractures } \\
\text { with } \\
\text { angulation } \\
\text { without } \\
\text { dislocation }\end{array}$ & $\begin{array}{l}\text { Collum } \\
\text { fractures } \\
\text { with } \\
\text { overriding }\end{array}$ \\
\hline & & \multicolumn{2}{|c|}{$\begin{array}{l}\text { Condylar process out of } \\
\text { the glenoid fossa }\end{array}$} & & \multicolumn{2}{|c|}{$\begin{array}{l}\text { Condylar process in the } \\
\text { glenoid fossa }\end{array}$} \\
\hline $\begin{array}{l}\text { Spiessl and } \\
\text { Schroll } \\
\text { classification }\end{array}$ & $\begin{array}{l}\text { Class VI and } \\
\text { I }\end{array}$ & Class V & Class IV & Class I & & $\begin{array}{c}\text { Class II and } \\
\text { III }\end{array}$ \\
\hline $\begin{array}{c}\mathrm{ABC} \\
\text { classification }\end{array}$ & $A$ and $B$ & $\mathrm{C}$ & & & & \\
\hline
\end{tabular}



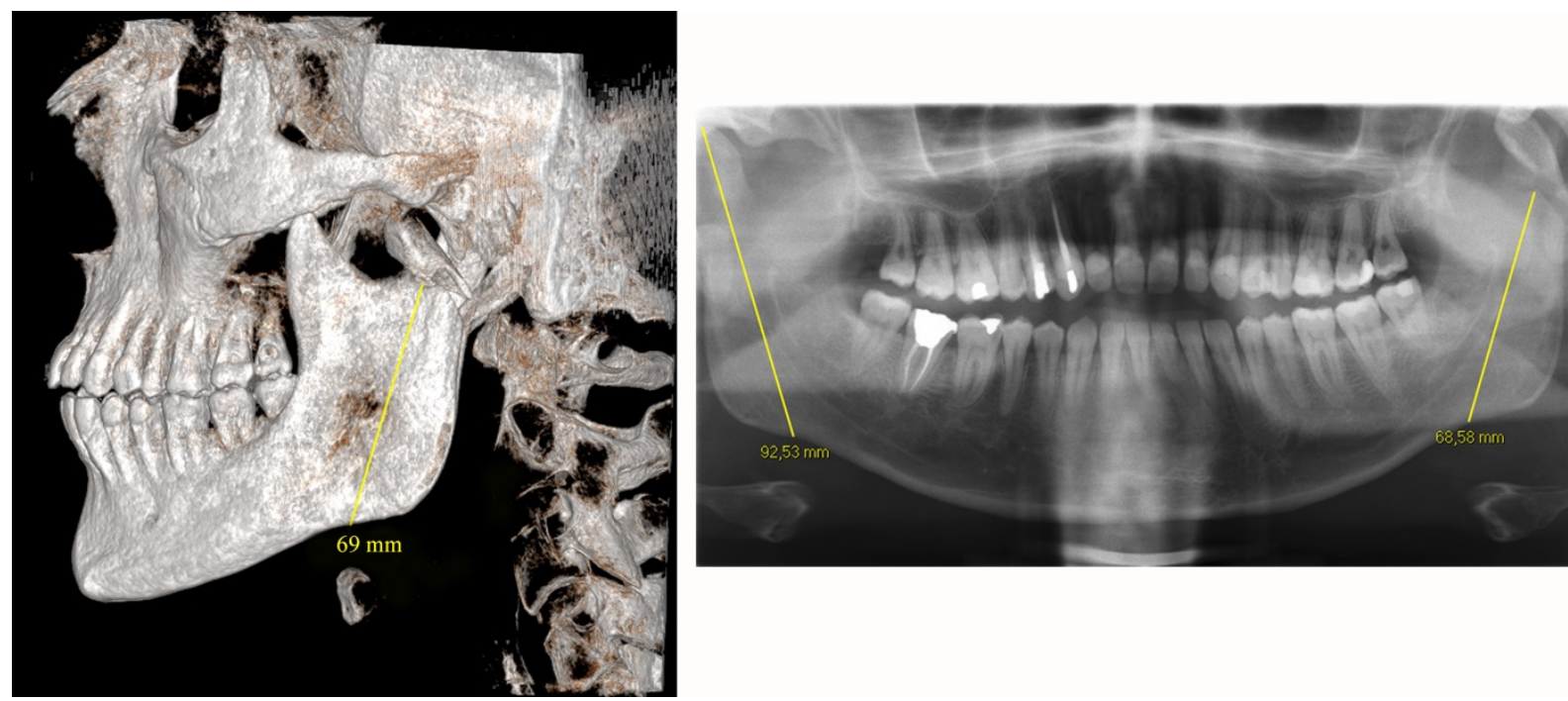

Figure 1 : Ascending ramus height measurement on CBCT three-dimensional reconstructions (left) and on panoramic X-ray (right).

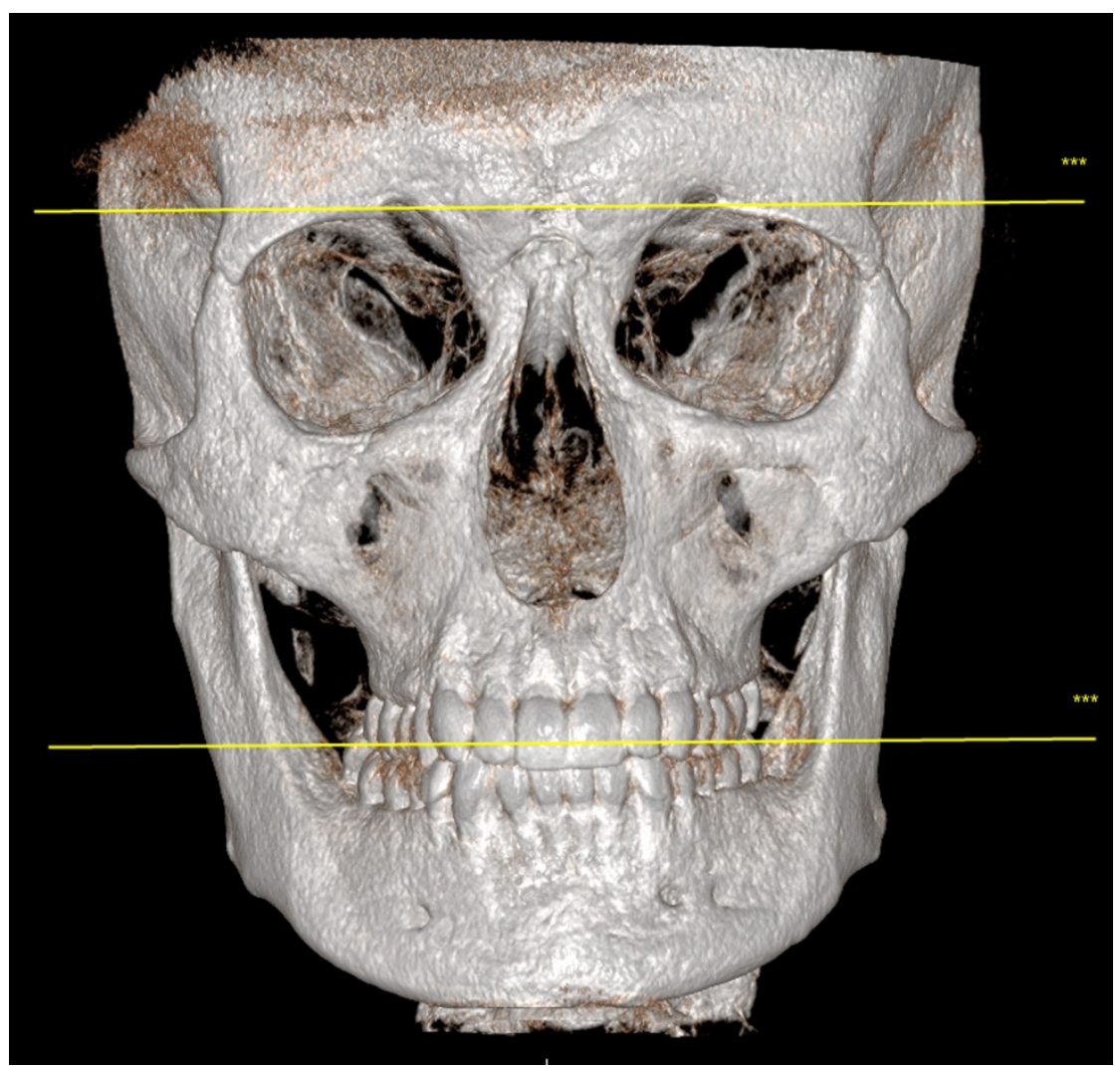

Figure 2: 3D frontal CBCT reconstruction showing occlusion plan 

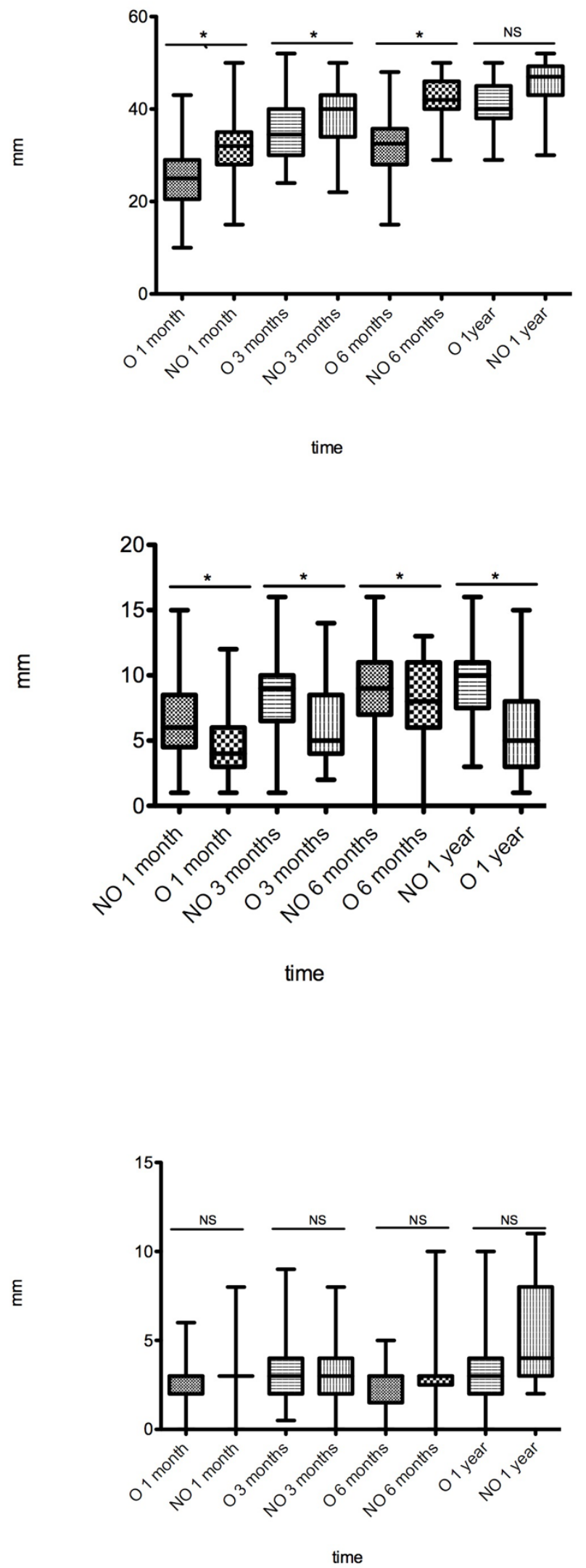

Figure 3 : Articular movements analysis : MMO (top), laterotrusion (middle) and propulsion (bottom) 0 : operated NO : non-operated NS : non-significant * : significant 